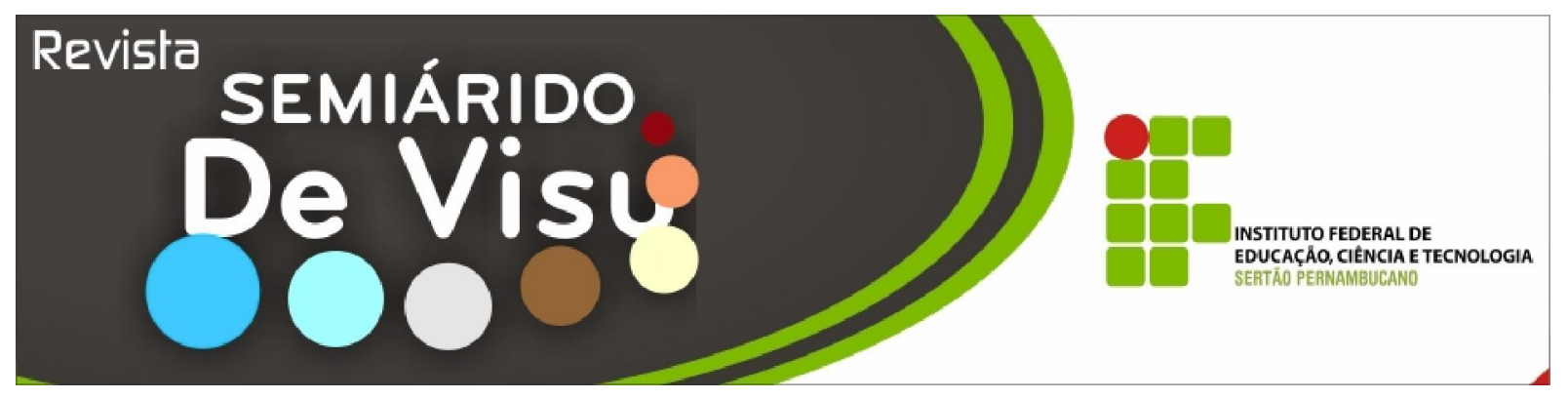

\title{
Espaço geográfico urbano, construção civil e meio ambiente: estudo comparativo das orlas fluviais de Juazeiro/BA e Petrolina/PE
}

\author{
Clécia Simone Gonçalves Rosa Pacheco ${ }^{1}$, Emanuel Patrick de Campos ${ }^{1}$ \\ Instituto Federal de Educação Ciência e Tecnologia do Sertão Pernambucano - IF SERTÃO PE, BR 407, Km 08 - \\ Jardim São Paulo - Petrolina - PE - Brasil, CEP: 56.314-520. Telefone: (87) 2101-4300, E-mail: \\ clecia.pacheco@ifsertao-pe.edu.br, emanuelpatrickcampos@gmail.com
}

\begin{abstract}
RESUMO: O presente artigo busca demonstrar os resultados de uma pesquisa feita baseada na problemática acerca da construção civil nas áreas das orlas urbanas do rio São Francisco. Tal problemática foi caracterizada com base em dois questionamentos: Quais são as implicações do espaço geográfico à construção civil? Quais são as implicações da construção civil ao espaço geográfico? A referida pesquisa buscou investigar o espaço geográfico urbano onde estão localizadas as orlas fluviais de Juazeiro/BA e Petrolina/PE, buscando identificar as vantagens e desvantagens existentes nestas áreas para a construção civil e visando analisar as possíveis implicações ambientais ocasionadas pela construção civil no entorno urbano do rio São Francisco. Para desenvolvimento desta pesquisa utilizou-se a metodologia de pesquisa bibliográfica para subsidiar e fundamentar a análise teórica e a pesquisa de campo, para analisar o perfil do espaço geográfico urbano, in lócus, das orlas fluviais de Juazeiro e Petrolina (cidades vizinhas), a topografia da área, os tipos de solo predominantes nesta área, para analisar as vantagens e desvantagens destes aspectos à construção civil.
\end{abstract}

Palavras-chave: Geografia Urbana, Empreendimentos Civis, Preservação ambiental.

\section{Geographic space urban, civil construction and the environment: a comparative study of river edge of Juazeiro/BA and Petrolina/PE}

\begin{abstract}
This article seeks to demonstrate the results of a research carried out based on the problem about the construction in the areas of urban edges of the Sao Francisco river. This problem was characterized on the basis of two questions: What are the implications of the geographical space in civil construction? What are the implications of civil construction the geographic area? This study aimed to investigate the geographic space urban which is located at the river edges of Juazeiro/BA and Petrolina/PE, trying to identify the advantages and disadvantages exist in these areas for the civil construction and aiming to examine the possible environmental implications caused by construction in urban surroundings of the São Francisco river. For development of this research used the methodology of bibliographic research to support and substantiate the theoretical analysis and field research, to analyze the profile of the geographic area urban, a locus, the riverbanks river of Juazeiro and Petrolina (neighboring towns), the topography of the area, the soil types predominate in this area, to look into the advantages and disadvantages of these aspects to the civil construction.
\end{abstract}

Key Words: Geography Urban, Civil Projects, Environmental Preservation 
Clécia Simone Gonçalves Rosa Pacheco \& Emanuel Patrick de Campos

\section{Introdução}

\section{Caracterização do problema}

$\mathrm{O}$ presente artigo busca discutir e apresentar os dados parciais de um projeto registrado como Programa Institucional Voluntário de Iniciação Cientifica - PIVIC, feita no espaço geográfico urbano das orlas fluviais de Juazeiro/BA e Petrolina/PE. Tal pesquisa surgiu a partir da observação cotidiana da geógrafa e pesquisadora e do aluno do $4^{\circ}$ ano do curso de edificações, que por conviver diariamente o transitar neste espaço geográfico, lhes conferem uma analise diária da paisagem geográfica de ambas as cidades. Sendo assim, é possível observar alguns aspectos diferenciados no espaço geográfico de ambas as cidades, aspectos estes voltados, a localização geográfica, a topografia, tipos de solos, entre outros. É possível observar também que do lado da orla pernambucana há certa, proliferação de edifícios, o que tem movimentado a economia de ambas as cidades e que tem de modo direto e indireto, proporcionado o crescimento e fortalecimento de emprego e renda desta região.

Por outro lado, percebe-se também que na orla fluvial baiana não acontece o mesmo, no que tange a construção de edifícios significativos, o que nos leva a questionar se as razões que levam a não construção de edifícios do lado baiano tem a ver com os aspectos do espaço físico. Assim sendo, surgiram duas indagações que inicialmente parecem ser apenas uma, mas não são: quais são as implicações do espaço geográfico na construção civil e quais são as implicações da construção civil no espaço geográfico?

Além destes questionamentos, foi importante analisar quais são as implicações geoambientais, tanto na orla fluvial baiana quanto na pernambucana, provocadas pela construção civil nesta região, tendo em vista que é sabido que a construção civil é uma das maiores causadoras de impactos ambientais no Brasil nos dias atuais.
Partindo destes pressupostos introdutórios, buscou-se através da referida pesquisa desenvolver um estudo aprofundado sobre o espaço geográfico urbano onde estão localizadas as orlas fluviais de Juazeiro/BA e Petrolina/PE, buscando identificar as vantagens e desvantagens existentes nestas áreas para a construção civil, analisando as possíveis implicações ambientais ocasionadas pela construção civil no entorno do rio São Francisco. Sendo assim, elencaram-se os seguintes objetivos para esta investigação:

1- Conhecer o perfil do espaço geográfico urbano onde estão inseridas as orlas fluviais de Juazeiro/BA e Petrolina/PE no que tange a localização e topografia;

2- Analisar se os tipos de solos que compõem as orlas de Juazeiro/BA e Petrolina/PE são propícios à construção civil;

3- Analisar sobre as possíveis implicações ambientais ocasionadas no espaço geográfico de ambas as cidades, no trecho orla fluvial urbana, pela construção civil.

4- Elaboração de um Manual Geoambiental de Construção Civil Local, contendo os resultados da pesquisa, com o objetivo de ser uma fonte de pesquisa dos estudantes do curso técnico de edificações do Instituto Federal de Tecnologia do Sertão Pernambucano (em processo de construção).

\section{Caracterização da região onde foi desenvolvida a pesquisa}

A referida pesquisa ocorreu no contexto geográfico urbano das orlas fluviais de Juazeiro/BA e de Petrolina/PE, orlas estas separadas e ao mesmo tempo integradas pelo rio São Francisco.

Do lado baiano, é possível caracterizálo de acordo com os aspectos geofísicos da seguinte maneira: o relevo pode ser caracterizado como pediplano sertanejo, com a existência várzeas e terraços aluviais. Quanto aos aspectos sócio-econômicos Juazeiro tem crescido timidamente, e o que tem crescido é graças ao complexo agrícola existente no Vale do São Francisco, conhecido mundialmente pela exportação de frutas tropicais. Nos 
aspectos culturais herda traços da cultura africana, que vai desde a culinária, música, dança, arte, entre outros aspectos. A orla de Juazeiro é um cenário místico, que varia desde invasões (com bairros pobres) a áreas de comércio, bares, atrativos do público local (área de festas e diversões).

Do lado pernambucano, é possível identificar que o município de Petrolina, está inserido na unidade geoambiental da Depressão Sertaneja, que representa a paisagem típica do semiárido nordestino, caracterizada por uma superfície de pediplanação bastante monótona, relevo predominantemente suave-ondulado, cortada por vales estreitos, com vertentes dissecadas.

No que tange aos aspectos socioeconômicos Petrolina é hoje uma das cidades que mais cresce economicamente no Nordeste, graças ao mercado agrícola proporcionado pela agricultura irrigada e pela produção de vinhos. A construção civil é também uma área de forte crescimento gerando emprego e renda na região.

\section{Justificativa da pesquisa e revisão de literatura}

O geógrafo Milton Santos (1995) define espaço como acumulação desigual de tempos. Nessa perspectiva, o espaço geográfico é coagulação do trabalho social, materialização de idéias e de ações das sociedades sobre a natureza. $\mathrm{O}$ espaço materializa diferentes tempos sociais e, sua gênese e evolução constituem o objeto da geografia. É nesse espaço geográfico que são construídas casas, prédios e edifícios, que proporcionam aos seres humanos os seus habitats, e também é neste mesmo espaço que o setor da construção civil promove emprego e renda em nosso país.

A Construção Civil é reconhecida como uma das mais importantes atividades para o desenvolvimento econômico e social, e por outro lado, comporta-se, ainda, como grande geradora de impactos ambientais, quer seja pelo consumo de recursos naturais, pela modificação do espaço geográfico ou pela geração de resíduos.
De acordo com Pinto (2005), o setor tem um grande desafio: como conciliar uma atividade produtiva desta magnitude com as condições que conduzam a um desenvolvimento sustentável consciente, menos agressivo ao meio ambiente? É uma pergunta, embora antiga, ainda sem respostas satisfatórias. Sem dúvida, por ser uma questão bastante complexa, requer grandes mudanças culturais e ampla conscientização.

A indústria da construção civil tem uma participação de aproximadamente $40 \%$ na economia mundial (Hansen, 2008). Isto mostra o tamanho desta indústria e quanto ela influencia não só na economia, mas também no meio ambiente e na sociedade como um todo. Porém ela é uma indústria muito abrangente e diversificada, onde, têm-se um grande desafio na introdução de melhorias e quebras de paradigmas. Mas devido a esta abrangência, qualquer modificação introduzida traz resultados muito significativos.

Segundo Caputo (2008, p.4), “constitui requisito prévio para o projeto de qualquer obra, sobretudo de vulto local, estudo das rochas, solos, minerais que o compõem, bem como a influencia da presença da água sobre ou sob a superficie da crosta". Ainda de acordo com o autor, tais estudos são indispensáveis, para se alcançar a "boa engenharia", isto é, aquela que garanta a necessária condição de segurança e, também, de economia. Este estudo é denominado de Mecânica dos Solos e, além dele, o autor destaca a importância dos estudos sobre as Ciências da Terra, denominação de Krynine e Judd (1961) e, dentre elas destaca-se a Geomorfologia ou Geografia Física, que é o estudo do presente à luz do passado, ou seja, é a disciplina responsável por estudar os aspectos físicos do espaço geográfico.

A Mecânica dos Solos estuda o comportamento do solo sob o aspecto da Engenharia Civil, pois é o solo que cobre o substrato rochoso e provém da desintegração e decomposição das rochas, mediante a ação dos intemperismos físico e químico. Assim, de maneira geral, por causa da sua heterogeneidade e das suas propriedades bastante complexas, não existe modelo 
matemático ou um ensaio em modelo reduzido que caracterize, de forma satisfatória, o seu comportamento. Atualmente, a Mecânica dos Solos situa-se dentro de um campo mais envolvente que congrega ainda a Engenharia de Solos (Maciços e Obras de Terra e Fundações) e a Mecânica das Rochas. Esta área, denominada Geotecnia, tem como objetivo estudar as propriedades físicas dos materiais geológicos (solos, rochas) e suas aplicações em obras de Engenharia Civil, quer como material de construção quer como elemento de fundação.

Segundo Silva (2009), o significado da palavra solo não é o mesmo para todas as ciências que estudam a natureza. Para fins de Engenharia Civil, ele é definido como uma mistura natural de um ou diversos minerais (às vezes com matéria orgânica) que podem ser separados por processos mecânicos simples, tais como, agitação em água ou manuseio. Em outras palavras, o solo é todo material que possa ser escavado, sem o emprego de técnicas especiais, como, por exemplo, explosivos. Mediante tais aspectos é essencial o conhecimento aprofundado do perfil dos solos para a eficiência das construções e para evitar a degradação do meio ambiente.

Como os edifícios são produtos com longa vida útil, no que tange à fase de uso, segundo Ceotto (2008) é responsável por parcela significativa de impacto ambiental. Os edifícios que não contemplaram a sustentabilidade nas fases iniciais há grande consumo de energia, de água e grande geração de resíduos, especialmente esgoto e lixo doméstico. Durante os vários anos de uso, além da manutenção, surge a necessidade de melhorias tais como revitalização da pintura, novos revestimentos de paredes, pisos e tetos, novas instalações prediais que geram novos consumos e resíduos. Existirá, portanto, a necessidade de projetos que contemplem adaptações tecnológicas sustentáveis para manutenção e reforma, além de espaços flexíveis que atendam às necessidades dos futuros usuários, para um maior tempo de uso.
Este mesmo autor cita vários impactos ambientais causados pela construção civil inadequada, Ceotto (2008):

- A operação dos edifícios consome mais de $40 \%$ de toda energia produzida no mundo;

- Consome $50 \%$ da energia elétrica e $20 \%$ do total de energia produzida no Brasil;

- A construção civil gera de $35 \%$ a $40 \%$ de todo resíduo produzido na atividade humana;

- $\mathrm{Na}$ construção e reforma dos edifícios se produzem anualmente perto de 400 $\mathrm{kg}$ de entulho por habitante, volume quase igual ao do lixo urbano;

- A produção de cimento gera $8 \%$ a $9 \%$ de todo o $\mathrm{CO}_{2}$ emitido no Brasil, sendo $6 \%$ somente na descarbonatação do calcário;

- Assim como o cimento, a maioria dos insumos usados pela construção civil é produzida com alto consumo de energia e grande liberação de $\mathrm{CO}_{2}$.

Já na teoria do Empuxo de Rankine (1857, p. 15), ele aborda sob o estado de equilíbrio plástico para superfície horizontal, e afirma que:

\begin{abstract}
A grandeza e distribuição das pressões laterais de solo (empuxos dos solos) são dependentes dos deslocamentos da parede das pressões verticais aplicadas. Assim, é importante estudar o comportamento do solo no estado de equilíbrio plástico, onde a tensão cisalhante iguala-se à resistência ao cisalhamento em determinado plano. Neste caso, as pressões laterais são determinantes.
\end{abstract}

Com base em todos estes pressupostos elencados, justifica-se a referida pesquisa pela real necessidade de maior conhecimento acerca do espaço geográfico urbano das orlas de Juazeiro/BA e Petrolina/PE no que tange à localização, à topografia, aos tipos de solos e analisá-los do ponto de vista da viabilização da construção civil nestas áreas, buscando enfatizar a necessidade de analise dos possíveis 
impactos ambientais causados por este setor de atividade nesta região.

\section{Relevância da pesquisa}

A referida pesquisa tem um caráter inovador, onde se buscou fazer uma análise do perfil geográfico do espaço urbano das orlas fluviais de Juazeiro e Petrolina, onde foi de crucial importância à contribuição das tecnologias no desenvolvimento desta pesquisa, visto que foi necessário fazer a utilização de aparelho de topografia para analisar o relevo do local, material de escavação do solo para fazer analise dos tipos de solos, de computador para anotar todos os dados pesquisados, entre outros aspectos relevantes que envolvem a tecnologia. No que tange aos aspectos socioeconômico e cultural, é pertinente enfatizar a importância da preservação ambiental e da sustentabilidade como fatores essenciais para a valorização dos espaços urbanos, essenciais também na melhoria das condições sócio-econômicas, além do caráter relevante da preservação do lugar, do espaço geográfico local, como contribuição cultural da população em questão.

\section{Material e métodos}

A análise comparativa das orlas fluviais envolveu três etapas principais: a modelagem do seu relevo com o nivelamento altimétrico topográfico, a elaboração de um mapa geológico indicando as concentrações de solos e a construção do Manual Geoambiental de Construção Civil Local.

Quanto ao nivelamento altimétrico com determinação de seções transversais, foi feito o nivelamento altimétrico nas duas orlas com os seguintes equipamentos: nível óptico $\mathrm{Ni}$ 93, baliza (comprimento $=4 \mathrm{~m}$ ). $\mathrm{Na}$ orla petrolinense, foi optado por um estaqueamento de $20 \mathrm{~m}$ (cinco estacas) enquanto na orla juazeirense foi utilizado um estaqueamento de $10 \mathrm{~m}$ (três estacas). Para a determinação de seções transversais, calcularam-se duas cotas orientadas por retas perpendiculares ao eixo de nivelamento que interceptam as estacas.
Ressalta-se que a distância entre cotas para seção transversal foi de $3 \mathrm{~m}$.

No que diz respeito ao nivelamento altimétrico com determinação de seções transversais para a elaboração dos mapas geológicos, foram realizados os ensaios de construção de curva granulométrica, determinando as porcentagens de solos constituintes segundo a classificação ABNT de dimensão de partículas e a classificação A.S.T.M. (American Society for Testing Materials), para peneiras (ABNT/NBR 6502/95).

No que tange à elaboração de um mapa geológico indicando as concentrações de solos, fez-se o recolhimento de amostras dos solos das duas orlas fluviais, utilizando-se os seguintes instrumentos: estacas para marcar os pontos de coletas e pá de corte para recolhimento das amostras. O terreno foi dividido pela topografia (encosta) e pela textura (arenosa). Cavou-se cerca de quinze (15) buracos, em pontos distintos das duas orlas, em formato $\mathrm{V}$, com cerca de, $25 \mathrm{~cm}$ de profundidade, retirando-se cerca de 1-2 kg de amostra.

Em se tratando da analise dos impactos ambientais causados pela construção civil, foram observadas e analisadas as áreas estudadas que ficam no entorno das orlas de Juazeiro e Petrolina, partindo do pressuposto da identificação de deposição de resíduos da construção civil. Assim, o método de pesquisa nesse item, foi o dedutivo/indutivo, onde se partiu do geral para o local.

Quanto ao Manual Geoambiental o método utilizado para a elaboração do mesmo, parte desde os pressupostos teóricos que embasaram essa pesquisa até a conclusão dos resultados práticos finais desta pesquisa, que serão minuciosamente descritos no Manual.

\section{Levantamento de dados}

A fase de levantamento de dados envolveu a coleta de material bibliográfico que fundamentaram as idéias teóricas preconizadas na revisão de literatura e os dados da pesquisa de campo envolveram dados geológicos, estruturais e topográficos que serviram de base pratica para o desenvolvimento do trabalho. 
Clécia Simone Gonçalves Rosa Pacheco \& Emanuel Patrick de Campos

\section{Nivelamento topográfico altimétrico (NTA)}

Foi utilizado o método de Nivelamento Topográfico Altimétrico para a análise do relevo característico das duas orlas. Esse método é definido como o conjunto de métodos e procedimentos necessários à obtenção das distâncias verticais (alturas e diferenças de nível - DN) em relação a uma superfície de nível de comparação. O objetivo da altimetria, como dito, é o conhecimento da superfície externa da terra (relevo).

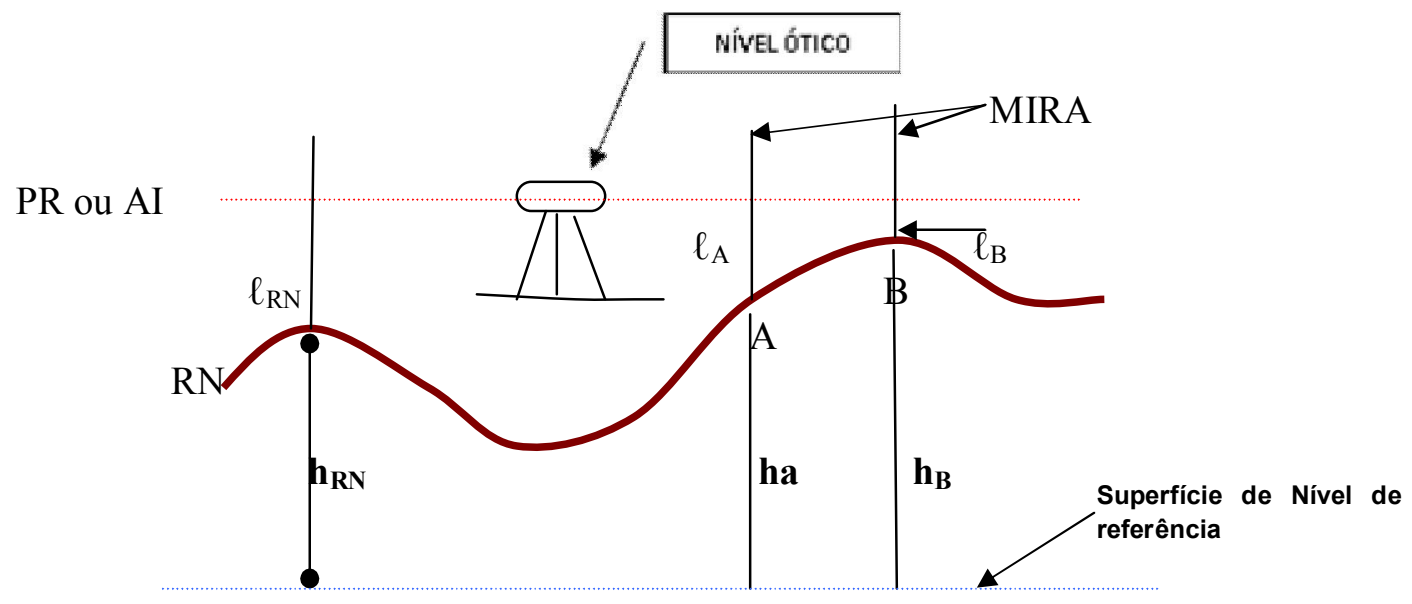

(Fonte: SANTOS, 2010)

Conforme visto, o referido método foi executado com o auxílio do instrumento nível óptico e mira-falante. É pertinente registrar que os instrumentos para a execução dessa importante etapa da pesquisa foram concedidos pelo Instituto Federal de Educação Ciência e Tecnologia do Sertão Pernambucano.

Para verificação da coerência de dados coletados em campo, foi utilizado o método de verificação de dados por cardenetas de nivelamento e contranivelamento. Foi estabelecida uma cota de projeto $(\mathrm{hb}=383074)$ para determinação de plano de referência (PR). A seguir estão indicadas as tabelas de cadernetas de nivelamento e contranivelamento do local pesquisado.

Tab. 1.1 Caderneta de nivelamento da orla petrolinense

\begin{tabular}{|c|c|c|c|c|c|c|c|c|c|}
\hline \multirow[t]{2}{*}{ ESTACAS } & \multicolumn{2}{|c|}{ VISADAS } & \multirow[t]{2}{*}{$\begin{array}{l}\text { PLANO DE } \\
\text { REFERENCIA }\end{array}$} & \multicolumn{2}{|c|}{ COTAS } & \multicolumn{4}{|c|}{$\begin{array}{l}\text { COTAS PARA DETERMINAÇÃO DE SEÇÕES } \\
\text { TRANSVERSAIS (Cota Base }=383781 \text { ) }\end{array}$} \\
\hline & RÉ & VANTE & & TERRENO & PROJETO & e1 & e2 & d1 & $d 2$ \\
\hline EO & 1503 & & 385090 & & 383074 & 383493 & 383416 & 383480 & 383293 \\
\hline E1 & 1149 & 2329 & 384736 & 382761 & & 382853 & 383004 & 382684 & 382624 \\
\hline E2 & 1138 & 1748 & 384725 & 382988 & & 382203 & 382276 & 382003 & 381896 \\
\hline E3 & 1363 & 2349 & 384950 & 382376 & & 380943 & 380975 & 380849 & 380866 \\
\hline E4 & & 1898 & & 383052 & & 380389 & 380360 & 380371 & 380296 \\
\hline
\end{tabular}

Fonte: Pesquisadores (2011) 
Clécia Simone Gonçalves Rosa Pacheco \& Emanuel Patrick de Campos

Tab. 1.2 Caderneta de contranivelamento da orla petrolinense

\begin{tabular}{|c|c|c|c|c|c|c|c|c|c|}
\hline \multirow[t]{2}{*}{ ESTACAS } & \multicolumn{2}{|c|}{ VISADAS } & \multirow[t]{2}{*}{$\begin{array}{l}\text { PLANO DE } \\
\text { REFERENCIA }\end{array}$} & \multicolumn{2}{|c|}{ COTAS } & \multicolumn{4}{|c|}{$\begin{array}{l}\text { COTAS PARA DETERMINAÇĀO DE SEÇOES } \\
\text { TRANSVERSAIS (Cota Base }=383781)\end{array}$} \\
\hline & REE & VANTE & & TERARENO & PROUETO & e1 & ez & d1 & $d 2$ \\
\hline E4 & 1624 & & 384676 & & 383052 & 383493 & 383416 & 383.480 & $383: 293$ \\
\hline E3 & 1820 & 1320 & 385176 & 383356 & & 382853 & 383004 & $38: 2684$ & 3822624 \\
\hline E2 & 1289 & 1115 & 385350 & 384061 & & 382203 & 382276 & $38: 2003$ & 381896 \\
\hline E1 & 1432 & 895 & 385887 & 384455 & & 380943 & 380975 & 380849 & 380866 \\
\hline EO & & 768 & & 383060 & & 380389 & 380360 & 380371 & 380296 \\
\hline
\end{tabular}

Fonte: Pesquisadores (2011)

Nas tabelas acima, é possível perceber os pontos para determinação de cotas (E0, E1, E2, E3, E4). Estão também representadas, as técnicas de análise do relevo durante o nivelamento altimétrico (visadas ré e vante) determinadas a partir do instrumento nível óptico. A cota de projeto foi determinada através da inclinação relativa da referida orla (i $=0,000275 \%)$. As cotas para determinações transversais foram nescessarias para detalhar o comportamento do terreno onde "e1", "e2" significa as cotas determinadas a oeste do eixo do nivelamento; d1 e d2 significam as cotas determinadas ao leste do eixo de nivelamento.

A margem de erro foi $14 \mathrm{~mm}$, o que cientificamente se torna irrelevante para um nivelamento de $80 \mathrm{~m}$. Na orla de Juazeiro, foram utilizados somente três pontos para determinação de cotas (E0, E1, E2) conforme podemos observar nas cadernetas a seguir.

Tab. 2.1 Caderneta de nivelamento da orla juazeirense

\begin{tabular}{|c|c|c|c|c|c|c|c|c|c|}
\hline \multirow{2}{*}{ ESTACAS } & \multicolumn{2}{|c|}{ VISADAS } & \multicolumn{2}{c|}{$\begin{array}{c}\text { PLANO DE } \\
\text { REFERÊNCIA }\end{array}$} & \multicolumn{3}{c|}{ COTAS } & \multicolumn{3}{c|}{$\begin{array}{c}\text { COTAS PARA DETERMINACCÃO DE SEÇÕES } \\
\text { TRANSVERSAIS (Cota Base = 383687) }\end{array}$} \\
\cline { 2 - 11 } & RÉ & VANTE & & TERRENO & PROJETO & e1 & e2 & d1 & d2 \\
\hline E0 & 2015 & & 386937 & & 384922 & 383417 & 383179 & 383480 & 383293 \\
\hline E1 & & 2211 & & 384726 & & 382828 & 383004 & 382684 & 382624 \\
\hline E2 & & 2318 & & 384619 & & 382178 & 382276 & 382003 & 381896 \\
\hline
\end{tabular}

Fonte: Pesquisadores (2011)

Tab. 2.2 Caderneta de contranivelamento da orla juazeirense

\begin{tabular}{|c|c|c|c|c|c|c|c|c|c|}
\hline \multirow[t]{2}{*}{ ESTACAS } & \multicolumn{2}{|c|}{ VISADAS } & \multirow[t]{2}{*}{$\begin{array}{l}\text { PLANO DE } \\
\text { REFERENCIA }\end{array}$} & \multicolumn{2}{|c|}{ COTAS } & \multicolumn{4}{|c|}{$\begin{array}{l}\text { COTAS PARA DETERMINAÇÃO DE SEÇŌ̃SS } \\
\text { TRANSVERSAIS (Cota Base }=383687 \text { ) }\end{array}$} \\
\hline & RÉ & VANTE & & TERRENO & PROJETO & e1 & $\mathrm{e} 2$ & d1 & d2 \\
\hline E2 & 2426 & & 387045 & & 384619 & 383417 & 383179 & 383480 & 383293 \\
\hline E1 & & 2328 & & 384717 & & 382828 & 383004 & 382684 & 382624 \\
\hline EO & & 2131 & & 384914 & & 382278 & 382276 & 382003 & 381896 \\
\hline
\end{tabular}

Fonte: Pesquisadores (2011)

Para a orla de Juazeiro, foi calculado um índice de inclinação de $0,01515 \%$. Todas as explicações dadas para realização da pesquisa na orla petrolinense, utilizou-se as mesmas técnicas para a orla juazeirense.

\section{Elaboração de mapa geológico}

No que diz respeito à elaboração de um mapa geológico, houve a coleta das amostras in lócus, onde se dividiu os terrenos a partir da topografia e textura, fez-se cortes no solo em formato de V, com cerca de $25 \mathrm{~cm}$ de profundidade. Colheram-se as amostras de 
Clécia Simone Gonçalves Rosa Pacheco \& Emanuel Patrick de Campos

pontos diferentes do solo para fins de caracterização e colocaram-se as amostras de solos em sacos plásticos separados e etiquetados. O material foi levado para analise no laboratório de solos do IF Sertão-PE.

\section{Impactos ambientais (IA) e Manual geoambiental}

A análise dos impactos ambientais no entorno das orlas analisadas foi feita a partir da observação, identificação de resíduos de construção civil depositados em trechos inadequados das orlas, principalmente da orla pernambucana. Quanto ao Manual Geoambiental, este já está sendo elaborado em sua parte teórica, restando apenas à escrita da parte prática, com os achados da pesquisa de campo.

\section{Resultados e discussão}

Conforme visto nas tabelas anteriores, a orla de Juazeiro (BA) apresenta um maior índice de inclinação de relevo em comparação com a orla petrolinense. Um dos parâmetros da teoria de Rankine (1837) Apud Machado e Machado (2002) sobre o equilíbrio de maciços terrosos define a relação direta entre o índice de inclinação de um relevo e possibilidades de cargas aplicadas no mesmo.

Levando em conta a teoria de Rankine, teremos as seguintes implicações a cerca do espaço geográfico das referidas orlas:

$\checkmark$ Índice de inclinação (orla Juazeiro) $=$ $0,01515 \%$ (tende a receber menores cargas para uma determinada condição de estabilidade definida para as duas orlas). Assim sendo, não é viável a construção de edifícios que ultrapassem dez andares, porém, ressalta-se que é possível mediante investimentos em tecnologia.

$\checkmark$ Índice de inclinação (orla Petrolina) $=$ $0,000275 \%$ (tende a receber maiores cargas para uma determinada condição de estabilidade definida para as duas orlas), sendo possível e viável a construção de edifícios com dez ou mais andares.

Isso significa uma implicação para existência de diversos fatores geológicos que explicam a proliferação diferenciada de edifícios das duas orlas.

Portanto, o comportamento das superfícies das regiões meso-expansiva e frontal-expansiva das orlas de Petrolina e Juazeiro foram analisadas sobre a óptica Rankiniana da ação de pressões submetidas na envoltória de resistência das orlas. Dentre os fatores utilizados para a compreensão da resistência efetiva adquirida pelo solo estão o coeficiente de empuxo em repouso do solo e o ângulo-base médio da cunha de ruptura da região a ser analisada. (Rankine, 1837).

A determinação do coeficiente de empuxo em repouso $(\mathrm{K})$ do relevo pesquisado requer $\mathrm{o}$ conhecimento da constituição geológica local. Para solos arenosos, o coeficiente de empuxo em repouso varia de 0,4 a 0,8 , em caso de solos colapsivos a gama de valores de $\mathrm{K}$ é muito expressiva, sendo necessário o seu mapeamento geológico determinado para áreas que apresente o mínimo de $0,95 \mathrm{Ha}$ (Barros, 1994). Como o solo que apresenta a maior fração constitutiva é a areia com dimensão relativa 18 micrometros, o coeficiente de repouso será estimado em 0,7 , onde a maior fração é arenosa. Há grande porção siltosa na região de encontro às águas, mas a maior parte é arenosa.

Ainda com relação a analise dos solos das orlas, há indicação de concentração de solos, com formação arenítica e argilosa e as suas respectivas tensões admissíveis a $1,5 \mathrm{~m}$ de profundidade. Há predomínio dos vertissolos (VC) do lado baiano "que compreende solos constituídos por material mineral apresentando horizonte vértico e pequena variação textural ao longo do perfil, nunca suficiente para caracterizar um horizonte B textural" e cambissolos (CX) do lado pernambucano "solos constituídos por material mineral com horizonte $\mathrm{B}$ incipiente subjacente a qualquer tipo de horizonte superficial, exceto hístico com $40 \mathrm{~cm}$ ou mais de espessura [...]" (Embrapa, 1999). 
No que tange à questão dos impactos ambientais da construção civil ao meio ambiente no entorno das duas orlas estudadas, foi possível observar durante a pesquisa de campo, a diversidade de lixo, resíduos e restos de entulhos, alguns oriundos da construção civil e outros não, o que fez chegar à premissa de que não há um controle rigoroso de fiscalização que "force" as empresas de construção civil a seguir as normas previstas na legislação ambiental brasileira, tanto na cidade de Petrolina quando na cidade de Juazeiro. Percebeu-se também em ambas as orlas, bastante erosão e compactação dos solos pelo desmatamento e mau uso dos recursos de solo e água o que leva ao aumento do assoreamento do rio São Francisco.

\section{Conclusões}

A construção civil é um ramo da indústria que dispõe de particularidades em cada obra executada, mas mesmo assim são primordiais os conceitos de minimização dos impactos ambientais. Não é necessária a busca de novas e grandiosas soluções, é primordial que se tenha noção dos cuidados básicos e que se procure colocá-los em pratica, mesmo nos pequenos empreendimentos de construção civil.

Especificamente, no que diz respeito, ao espaço geográfico foco desta pesquisa, estes cuidados necessitam ser redobrados, por se tratar de uma área que se localiza a margem de um curso de um rio, onde suas águas são utilizadas para múltiplas funções, que variam desde o consumo humano, animal até à agricultura irrigada. No entanto, é importante nesse momento conclusivo, respondermos aos questionamentos e indagações iniciais da pesquisa.

Com relação ao perfil topográfico das orlas pesquisadas, o ângulo base médio da cunha de ruptura local foi estimado no nivelamento altimétrico já mencionado anteriormente. $\mathrm{Na}$ orla petrolinense foi encontrado uma variação de 22 milímetros em 48 metros de análise, como a variação das cotas do greide não ultrapassam $3 \%$ da cota limite, podemos estimar que o ângulo base médio apresente o mesmo módulo da taxa de inclinação. Como na orla petrolinense a variação de 22 milímetros em 48 metros, a variação unitária será de $0,000275(0,0275 \%)$. $\mathrm{Na}$ orla juazeirense, com o avanço do espaço urbano para a região frontal da orla, ficou reduzido o espaço onde está concentrado o solo virgem. Já foi destacado no presente trabalho a existência de uma cota-limite situada a 20 metros da origem do nivelamento altimétrico e foi constatada a variação de 30,30 centímetros em 20 metros. A taxa de inclinação da orla juazeirense está com 0,01515 (1,515\%).

Conforme a teoria de Rankine sobre o comportamento de maciços terrosos, quanto maior for o ângulo-base médio da cunha de ruptura, menor são as pressões que a envoltória de resistência tende a receber para uma mesma fração de constituição geológica. No nosso, o ângulo-base da orla juazeirense torna-se mais expressivo em comparação a orla petrolinense. Podemos observar que as cargas a que estão submetidas o solo da orla de Juazeiro são, em grande parte, oriundas de edifícios de pequeno porte. Existem, ainda, alguns edifícios que ultrapassam a cota de 50 metros. O solo presente orla de Petrolina apresenta uma maior resistência característica, sendo solicitado por cargas originas de edifícios com acima dos 80 metros.

Com relação às tipologias de solos das orlas estudadas, é importante afirmar que não há melhor ou pior tipo de solo para utilização da construção civil. No entanto, a que levar em consideração que, as areias compactas, as muito compactas e argilas rijas e duras denunciam a existência de solos mais resistentes com maior capacidade de suporte de carga e menos susceptíveis a deformações. No entanto, as areias fofas e argilas tidas como mole, apontam solos menos resistentes, isto é, com menor capacidade de suportar cargas (Embrapa, 1999).

Em se tratando dos impactos ambientais na área pesquisada, é possível afirmar que as atividades da construção civil, por serem transformadoras do meio ambiente, estão submetidas ao licenciamento ambiental na área de influência do projeto. Este procedimento 
visa à análise dos impactos, definições das medidas corretivas e a elaboração de um acompanhamento e monitoramento dos impactos. O Decreto Federal no 99.274, de 6/6/90 - atualiza a Política Nacional do Meio Ambiente e trata da obrigatoriedade de licenciamento ambiental. Assim, nas áreas estudadas, perceberam-se alguns desperdícios de materiais, descarte de recurso renovável, impermeabilização e compactação do solo, entre outros, mas nada de grande magnitude, que pudesse afetar de forma severa o entorno, até porque, como já foi mencionado, toda e qualquer construção necessita de licenciamento prévio concedido pelos órgãos responsáveis locais. Por conta disso, destaca-se a relevância da elaboração e publicação de um Manual Geoambiental da Construção Civil Local, onde será mencionado com detalhes todos os aspectos da pesquisa e algumas sugestões da importância da valorização da construção civil sustentável.

A guisa de conclusão compreende-se que para se modificar os paradigmas vigentes é necessário conhecê-los, e assim, também é primordial que se conheça o espaço geográfico em que a construção está inserida, para que se possa fazer um estudo prévio dos possíveis impactos ambientais que a referida construção irá proporcionar à geografia local e do entorno, porque existem as implicações do espaço geográfico na construção civil, isto é, não são todos os espaços que podem ser ocupados para construção e, existem também as implicações da construção civil no espaço geográfico, que muitas vezes, causam impactos severos e irreversíveis ao meio ambiente.

\section{Agradecimentos}

Agradecemos ao IF SERTÃO-PE por conceder o material do laboratório de topografia necessários na pesquisa de campo e o laboratório de solos. Especificamente agradecemos ao professor Edvaldo do IF Sertão-PE (professor de topografia), pela contribuição em elucidar aos dados topográficos da pesquisa de campo pós-coleta.
Agradecemos também aos alunos do $4^{\circ}$ ano do curso técnico em edificações (hoje, Técnicos em Edificações), Luciano e Júlio César pela colaboração na pesquisa de campo.

\section{Referências}

ASSOCIAÇÃO BRASILEIRA DE NORMAS TECNICAS (ABNT/NBR 6502/95). Rochas e Solos. Comitê Brasileiro de Construção Civil CE - 02:004.05. Comissão de Estudo de Rochas e Solos NBR 6502 - Rocks and soils Terminology Descriptors: Rock. Soil. Válida a partir de 30.10.1995. Disponível em: < http://www.ebah.com.br/content/ABAAAAyA

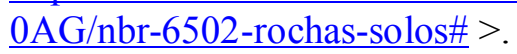

BARROS, P. L. A. Empuxo exercido por maciço não homogêneo sobre muros de arrimo. Simpósio de Informática em Geotecnia. Associação Brasileira de Mecânica dos Solos. São Paulo: 1994, p. 156-166.

BELTRAME, Eduardo de Sousa. Meio Ambiente na Construção Civil. Artigo Publicado e Disponível em: $<$ http://www.eduardo.floripa.com.br/download/ Artigo meio ambiente.pdf $>$. Acesso em Junho de 2011, às $18 \mathrm{~h} 30 \mathrm{~min}$.

CAPUTO, Homero Pinto. Mecânica dos Solos e suas aplicações. Vol. 1. 6 Ed. Rio de Janeiro: LTC, 2008.

CEOTTO, Luiz Henrique. A Construção Civil e o Meio ambiente: $1^{\mathrm{a}}$ parte; $2^{\mathrm{a}}$ parte; $3^{\mathrm{a}}$ parte. Notícias da Construção, Ed. 51 a 53, São Paulo, SP. Disponível em: < http://www.sindusconsp.com.br/secoes.asp?sub categ=74\&categ=16> . Acesso em: 22 de ago. 2008.

Decreto Federal no 99.274, de 6/6/90. Política Nacional do Meio Ambiente. Disponível em: $<$ http://www.planalto.gov.br/ccivil_03/decreto/ antigos/d99274.htm $>$ Acesso em: julho de 2011. 
Clécia Simone Gonçalves Rosa Pacheco \& Emanuel Patrick de Campos

EMBRAPA: Sistema Brasileiro de Classificação de Solos. 2 ed. Rio de Janeiro: EMBRAPA - SPI, 1999. Disponível em: < http://pt.scribd.com/doc/20796155/73/VERTIS

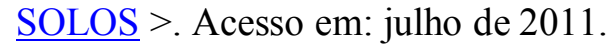

GRECO, U.R. Active earth thorust on cantilever in walls em general conditions. Soils an Fundations. Tokyo, v. 39, n. 06, p. 65-78, 1999. In: SILVA, Hélio Costa. Estudo da influencia do empuxo lateral causado por grãos nas paredes de grandes solos horizontais. Dissertação de Mestrado Profissionalizante em Engenharia. UFRGS, 2002.

HANSEN, Sandro. Gestão Socioambiental: Meio Ambiente na Construção Civil. Florianópolis, SC. SENAI/SC, 2008.

KRYNINE, D. P. \& JUDD, W. R. Princípios de Geologia y Geotecnia para Igenieros. 1961 .

MACHADO, S. L. e MACHADO, F. C. (2002), Apostila de Mecânica dos Solos, Escola Politécnica, UPBA.

PINTO, Tarcisio de Paulo. (coord.) Gestão Ambiental de Resíduos da Construção Civil: a experiência do SindusCon-SP. Obra Limpa: I \& T: SindusCon/SP, 2005.

SANTOS, Milton. Considerações acerca do Espaço Geográfico. Apostila do Concurso de Diplomata do IRBr/Cespe UnB em 1995.

SANTOS, V. O. dos, et al. Aplicação do Nivelamento Geométrico com Nível Óptico para Monitoramento de Recalques. Anais $26^{\mathrm{a}}$ JAI. UFSM, 2010. Disponível em: $<$ http://portal.ufsm.br/jai/anais/trabalhos/trabal ho $1001236885 . h t m ~>$. Acesso em: abril de 2011.

SILVA, Ana Patricia de Jesus. Apostila de Mecânica dos Solos do Curso de Engenharia Civil. UP/RN. Universidade Pontiguar, 2009.

Teoria de Rankine, (1857). Disponível em: < http://pt.scribd.com/doc/57934617/Teoria-di-

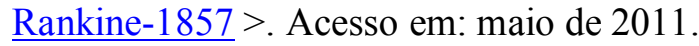

